\title{
Thomas Szanto: Bewusstsein, Intentionalität und mentale Repräsentation. Husserl und die analytische Philosophie des Geistes
}

\section{De Gruyter, Berlin, 2012 (Quellen und Studien zur Philosophie, Band 107), ISBN 978-3-11-027723-4, 654 pp, 129,95 €, \$182.00 (hardbound)}

\author{
Gianfranco Soldati \\ Published online: 1 February 2014 \\ (C) The Author(s) 2014. This article is published with open access at Springerlink.com
}

By the time of the Prolegomena (1900), Husserl took phenomenology to be a philosophical method that stands in opposition to naturalism, of which psychologism was supposed to be a particularly pernicious instance. Husserl was not the only philosopher at the turn of the century to oppose psychologism. Among his fellow campaigners one finds Frege, who played a decisive role in the development of socalled analytic philosophy, and Dilthey, who stands at the roots of contemporary hermeneutics. When it comes to issues concerning the origins of phenomenology, as opposed to other traditions, anti-psychologism in particular, and anti-naturalism in general, cannot be used as discriminative criteria. One would need to determine what is specific to the phenomenological brand of anti-naturalism.

Consider some of the claims shared by most anti-naturalists in Husserl's time. Judgments have a specific kind of content, called "proposition," "state of affairs" or "thought." Contents of that kind are original truth-bearers and they stand in logical relations to each other. Neither truth nor logical validity can be reduced to properties or relations of any other kind (e.g. causal, spatial or temporal). The mind, and its main achievement, knowledge, has a normative character that blocks naturalistic reduction. Husserl contributed decisively to establish this view, but one need not adopt Husserlian phenomenology in order to endorse it. This is as true today as it was more than a century ago. So it does not suffice to believe that judgments have a specific kind of content, and that the mind has an irreducibly normative dimension, in order to count as an heir of phenomenology.

What else, if neither anti-naturalism as such nor the defense of the normativity of the mind, could then be used in order to determine the specificity of phenomenological anti-naturalism? The classical answer is: transcendental phenomenology. Thomas Szanto's book is a contribution to the articulation and understanding of that

G. Soldati $(\bowtie)$

Département de Philosophie, Université de Fribourg, Avenue de l'Europe 20, 1700 Fribourg,

Switzerland

e-mail: gianfranco.soldati@unifr.ch 
answer. It is an important contribution not only because of its size (654 pages) and of the number of authors taken into consideration (the bibliography covers 44 pages), but also and most significantly because of the way it relates transcendental phenomenology to issues in contemporary philosophy, such as the relation between intentionality and the phenomenal properties of consciousness (Chapter 1), the program of naturalizing intentionality (Chapter 2), the debate between internalism and externalism (Chapter 3), and the relation between the notion of representation and different forms of realism (Chapter 4).

Since the amount of material covered by Szanto's book is quite large, I shall concentrate on a series of related topics, the topics that are mentioned in the title of the book. These topics concern Szanto's analysis of intentionality and his views concerning the relation between intentionality, consciousness, and representation. Szanto is critical of a number of recent approaches, which he generally labels as "analytical," and he maintains that Husserl has suggested a radically different approach. I shall examine Szanto's understanding of that approach. As it happens, I find Szanto's suggestions on behalf of Husserl's theory of intentionality interesting but finally unpersuasive.

Chapter 1 is announced as presenting and defending two main theses, allegedly grounded in transcendental phenomenology (p. 16). The first is the thesis of the irreducible intentional correlation (p. 52), the second is the thesis of the intrinsic intentional relationality of consciousness (p. 56). The two claims are established in opposition to views that separate intentionality and phenomenal character (p. 16). The final view is that "consciousness is necessarily intentional consciousness and that intentionality is essentially a property of consciousness" (p. 16). So the view rules out both the possibility of "non-intentional, purely phenomenal conscious experiences" (p. 53) and the possibility of non-conscious intentional states (p. 57).

The first thesis involves the claim that "the (intrinsic) intentionality of consciousness and that which is given in some way in intentional conscious experiences stand in an irreducible, constitutive and unbreakable correlation to each other" (p. 52). Szanto thinks that this implies the claim that "the property of consciousness is nothing else than the intentional being-directed-on-something" (p. 56). Szanto opposes this view to what he calls the "dominant representational paradigm" (p. 44), which maintains that there is a mental representing entity that stands for a non-mental represented entity and, crucially, that the relation between them is a "non-conscious extensional-referential or/and causal [...] dependence" (p. 45). Contrary to that view, it is maintained that intentionality is no "causal, representational and/or referential relation" (p. 45). The relation between a conscious experience and its "objectualities" (Gegenständlichkeiten) is not causal because it is constitutive, and it is not representational (and not referential) because "what is given in consciousness (Bewusstseinsgegebenheiten) is not an entity internal to consciousness that represents an entity external to it" (p. 46).

There are various claims in the passages quoted above that ask for clarification. What prevents the relation between "the intentionality of consciousness" and that which is given in intentional conscious experiences from being representational? What has this to do with the issue of whether both are internal or external, or just one of them is? What is specifically transcendental, or even phenomenological, 
about the claim that intentionality is not a representational relation? Szanto says that intentionality cannot be causal, because it is constitutive. Why is Szanto opposing causal and constitutive? Could an object causing an experience not be a constitutive part of the experience? Transcendental phenomenology is obviously not in the business of naturalizing intentionality, so it shouldn't be expected to involve the reduction of intentionality to a causal relation. But what does the constitution claim then amount to? Is the idea that the objectualities are constituted by the experience, or by the subject having the experience?

In what follows I shall try to determine Szanto's answers to some of these questions. Most of the issues depend, unsurprisingly, on Szanto's view concerning the ontological status of the intentional relation and of its relata. We are told that from a phenomenological point of view an object is "a possible object of intentional consciousness" (p. 48; my emphasis) and that "an object is [...] intentional if there is an [...] intention, which is directed in some way on it" (ibid.). An object, or rather an intentional object, is further said to be a phenomenon. "Phenomena in the phenomenological sense are essentially intentional objectualities, and more precisely all (actual and possible) intentional objectualities" (p. 50). So the object of an intentional experience is a phenomenon. The intentional object, thus the phenomenon $x$, is "constituted by consciousness when the giveness of $x$ (epistemically) depends in its objectual sense [...] on one or more acts of consciousness" (p. 54). These passages suggest the following view. An object is intentional when it is the possible object of an act of consciousness. So, say, some distant unknown star is an intentional object if it could be something someone sees or thinks about. But if the distant star has not yet been seen or thought of, then it has not yet been constituted as a phenomenon. So maybe the distant unknown star is not an intentional object unless it has been thought of or imagined as possible (notwithstanding well known problems concerning the identity relation between imagined, possible and actual objects). For something to be an intentional object, or phenomenon, it thus needs to be the object of some act of consciousness. But this dependence is said to be epistemic, and thus, I suppose, not ontological. Does this mean that although the unknown distant star exists independently of anyone having ever thought of it, it is not a phenomenon, an intentionally constituted object, unless one actually thinks of (imagines, etc.) it? There is an air of triviality about this claim, if it is read as meaning that the distant star is not something somebody has thought about until somebody actually thinks about it. In order to dissipate such doubts we need an alternative interpretation of what an intentional object, or phenomenon, is supposed to be.

The long Section 3 of Chapter 2 (pp. 178-251), called "Intentionality and Propositionality," is announced as presenting a "detailed analysis of Husserl's early theory of meaning and truth" (p. 18) and an "exposition of the analytical misinterpretation of the Husserlian theory of meaning and intentionality" (ibid). So this seems to be the place where an answer to some of our questions ought to be found. What one finds first, however, is a long criticism of the claim that all mental states are propositional attitudes. Szanto is certainly right to insist that Husserl did not share that view. But there is nothing particularly anti-naturalistic in rejecting it, and maintaining that perceptual experiences are representational does not commit 
one to the claim that they are propositional attitudes. Szanto appears to believe that the question about propositional attitudes is relevant for understanding the nature of intentionality. So let us look at it in a bit more detail.

A number of issues have to be distinguished to start with. One issue is whether it is generally correct to maintain that mental states involve an intentional relation to a proposition. Another issue is whether it is generally right to claim that mental states have representational content, whether this involves the contention that they have correctness conditions, and whether such conditions must be spelled out in propositional terms. It is one thing to deny that one can see the apple on the table without seeing that there is an apple on the table. It is another thing to say that for one to visually experience an apple on the table it must be true that there is an apple on the table. The first claim contains the idea that seeing is (or is intimately related to) a propositional attitude. The second claim articulates conditions that must be satisfied for the perceptual experience to be correct. There is no direct step from one claim to the other. Most philosophers willing to defend the idea that perceptual experiences have presentational content would defend some version of the latter without accepting the former.

Szanto is critical of "representationalism" (p. $105 \mathrm{ff}$.), which he takes to be at the core of naturalism about the mind. He understands the question of the "constitution of intentionality" as being the question of what makes it the case that some "prima facie non-mental entities" (p. 97) are directed on something. And he submits that on the naturalistic conception the answer to that question is provided by a theory of representation (p. 96). Szanto argues that intentionality cannot be analyzed in representational terms. Does this mean that intentional states have no correctness conditions? And what has this to do with the question of naturalism?

A rather simple and probably common view is that representation is a natural function, a function that can be analyzed in fully naturalistic terms, and that an intentional state is a conscious state that has a representational function. To oppose the analysis of intentionality in terms of representation would then mean to reject the idea that what makes an intentional state conscious can be accounted for in representational terms. But in order to do so, one need not reject the idea that intentional states have representational content, whether propositional or not. Insisting on the fact that intentional states are necessarily conscious and that conscious states are necessarily intentional does not impinge on that issue. Intentional states may be necessarily conscious representations, and conscious states may be necessarily representational. For Szanto's line of argument to succeed, we need a reason to believe that there is a more profound relation between consciousness and intentionality. And we need to understand why that relation is supposed to be jeopardized by the idea that intentional states have representational content.

There are three common ways to obtain anti-reductionism about intentional states. Following a first line of thought, an intentional state is necessarily a state of a (conscious) subject: it is a state of something appearing in some way to somebody. So if the bearer of a representational state does not need to be a (conscious) subject, then a representational state is not an intentional state. On another line of thought, the specificity of intentional states lies in their objects, which are precisely 
intentional objects. Representational states can represent actual objects, states of affairs, facts, possible objects, maybe be even fictional entities, but not intentional objects. Intentional objects are objects that are essentially given to consciousness. In this sense they are essentially appearances or phenomena. Finally, on a third line of thought, intentional states are situated in the space of reasons; they are submitted to some kind of normative requirement. Representations do not stand under any such requirement, so representations are not intentional states. The three lines can of course be combined in order to yield the view that an intentional state is a state of a subject to whom things consciously appear in ways that provide him with reasons for forming beliefs and intentions to act. There is no direct path from any of those views to the rejection of the claim that experiences have representational content, if all that is meant is that they have properties in virtue of which they can be more or less correct, appropriate, or veridical. Does Szanto's view correspond to one of the positions mentioned above, and is he really arguing that it involves the rejection of representational content, or is he suggesting a further approach that would directly produce that result?

There are of course many different notions of representation and many different representational theories of the mind. Szanto discusses at least two theories that use very different notions of representation. One is the theory he labels the "representational theory of intentionality" (RTI) (pp. 106, ff.). The other is the theory of pictorial or symbolic representation criticized by Husserl in the Logical Investigations (p. 220). RTI is a fairly hybrid position that contains, among other things, the claims that mental states are representational and that they are individuated through their representational content (p. 109). Szanto thinks that this view stands at the basis of "representational verificationism," which holds that the attribution of a mental state must be empirically verifiable. Szanto suggests that Searle's claim that the "key to understanding representation is conditions of satisfaction" reveals a commitment to RTI (p. 111). Szanto rejects RTI, in part with arguments that concern representational verificationism rather than the very notion of satisfaction or correctness conditions. This is rather unwise, since one can certainly think that a judgment-say, that two and two is four-has conditions of satisfaction, which are indeed propositional, without assuming that the attribution and individuation of that state must be empirical. But apart from that, one wonders on what basis Szanto rejects the idea that Husserl took mental states in general to have representational content, since he describes him as holding, inter alia, that "representational matter and representing contents constitute the representational core of objectifying representations" (p. 217). The answer is that Szanto thinks that RTI has something in common with the rejected theory of symbolic representation. Husserl is said to reject "the representational view which understands the distinction between the real and the intentional contents of an act as a relation of symbolicpictorial representation or depiction, and thus transforms the phenomenologicaldescriptive distinction between the two parts of the content into an ontological-real distinction between 'real' and 'mere intentional' objects of 'internal' representations" (p. 220). This is supposed to stand in opposition to a view that "takes the two poles of the intentional relation to be two moments of the content of intentional experiences" (p. 210). 
There may be recent views that contain elements of the pictorial conception of representation (Szanto focuses, inter alia, on Fodor's hypothesis of the language of thought). But it would be rather surprising to learn that most philosophers working in the so-called analytic tradition, from Dummett to Davidson and from Evans to Peacocke, failed to learn the lesson Wittgenstein drew from his own earlier mistakes. To accept that a judgment, say, is true under certain conditions, is not to think that there is something in the mind that depicts those conditions, as a painting by van Gogh depicts a sunflower or a musical score stands toward musical performances. What is true, however, is that on the representational conception of the mind, an experience is an event in the stream of consciousness that represents conditions whose obtaining does not, at least not typically, depend on the mind. In this sense, the distinction is indeed a metaphysical one. So, leaving aside the issue about pictorial representation, what is wrong about this distinction, in Szanto's opinion, and what is the alternative Husserl is supposed to have suggested in spite of his representational jargon?

Szanto insists that, on Husserl's view, "in a mental representation [sic!] one is not directed on the representing real contents" but on the intentional object, through its "act-transcending directionality" (p. 224). RTI is instead said to hold that there is a "relation between a purely phenomenal state, the intentional experience, and an (internal) representative of an (external) object" (ibid). The experience is supposed to be directed on this internal representative, and not, as in Husserl's case, directly on the external object. Szanto quotes a telling passage where Husserl says that "when the intentional experience occurs, then [...] an object is eo ipso intentionally present" (ibid.).

Accepting the idea that a judgment has truth-conditions surely does not commit one to the claim that those conditions are "internal" and that they represent some external entity. It would be seriously mistaken, for instance, to qualify as "internal" Frege's notion of a thought (Gedanke), as the content of an act of judgment. It would also be wrong to say that the world, or some fact in the world, is represented by those truth-conditions. The idea must rather be that in a judgment the mind represents the world in a certain way, as satisfying certain conditions. Those external or "act-transcending" conditions are indeed what one's judgment is directed upon.

Theories of mental content often originate from concerns about the possibility of misrepresentation. General epistemic considerations are relevant in this respect. Some, if not most, of our knowledge is fallible. That means that in some cases what we believe could be false. False beliefs are not mental states of another kind; they are just what many of our true beliefs could be. So truth is not constitutive of belief. A belief does not dissolve simply by being false; there is still something one believes: a proposition. This kind of reasoning has its limits. It does not apply to knowledge, for instance. There is nothing one knows when one's belief is false. Nor does it apply to perception: there is nothing one sees when one hallucinates. And there is nothing one thinks about in a demonstrative thought, when the demonstrative reference fails to pick out an object. Cases of this kind might be used in order to start an argument against the idea that knowing, perceiving, and thinking always have representational content. So maybe Szanto's interpretation of 
Husserl's theory of intentionality should be read in the light of considerations of this kind. It is worth inquiring into such a suggestion. But before doing so, let me point out that whatever its merit, it can hardly be part of a general view about intentionality. The point made above about the origin of theories of content still remains. So even if some intentional experiences were non-representational, that alone would not suffice to make the general point Szanto is aiming at.

Szanto explicitly considers relational theories of perception in Section 2.6 of Chapter 3. He calls them "de-re conceptions of intentionality" (p. 375) and says that, following such views, "the fact that a subject has an attitude towards her own mental contents or to a proposition does not suffice for her mental state to be intentional" (pp. 373-374). So these views would not be instances of representationalism in Szanto's sense. But he rejects such views on Husserl's behalf, even for the limited case of perception. The problem concerns the status of the objects to which such experiences are supposed to stand in intentional relation: "these objects are characterized by Husserl as essentially intentional, and are thus not identical [sic!] to the real-existing, external and mind-independent objects" (p. 379). Now this is as clear as it is disappointing. For we started above from the assumption that the distinction between the real and the intentional object is epistemological, not metaphysical. But now it sounds as if it were a metaphysical distinction after all. So the unknown distant star can never become an object of consciousness. When we eventually look at it, we see some intentional object that is not identical with it.

With this result at hand, we obtain an answer to many of the questions raised so far. Szanto's position would belong to the second variety of antireductionism mentioned above: intentional experiences have essentially intentional objects. These objects are mind-dependent and as such have a constitutive relation to experience. There is an intimate relation between intentionality and consciousness because intentional objects depend on experiences. The relation between experiences and their objectualities is not representational because there is no representational content "in between" the experience and its intentional object. So perceptual experience and hallucination do not have a common representational content; they simply have different intentional objects. The same, one might surmise, ought to be said about true and false beliefs.

Some may find positions along such lines unattractive. It does not appear very elucidating, for instance, to explain the fact that intentionality is necessarily conscious through the assumption that intentional objects are necessarily minddependent. The real issue, it might be objected, was to explain the specificity of our conscious awareness of objects that are not supposed to be mind-dependent. It might further be questioned whether it is really an advantage to take all experiences to be relational in the same sense. If one can find good reasons to think that perceptual experiences and demonstrative judgments involve a relation to an object, it is less clear that the same kind of consideration applies to all judgments or to desires. It seems that both a desire and a perception are about something, are directed on something, but one should not conclude from that that they need to involve the same kind of relation to a mind-dependent entity. It might finally be questioned whether Szanto is really offering the most promising interpretation of Husserl's account of intentional experiences. After all it is Husserl himself who famously wrote: "It 
need[s] [...] to be acknowledged that the intentional object of a presentation is the same as its actual object, and on occasion as its external object, and it is absurd to distinguish between them. [...] This is plainly a merely analytic proposition" (Hua XIX/1: B 425).

One may protest that the remarks above rest on a misunderstanding of Husserl's transcendental idealism. The fact that an intentional object is not identical to a mind-independent object does not license the conclusion that it is mind-dependent. Indeed, Szanto opposes Husserl's transcendental idealism to a position called "subjective idealism" (p. 524), which involves the contention that "every possible object ontologically depends with respect to its existence [...] on consciousness" (p. 526). So, we should arguably conclude that an intentional object is neither minddependent nor mind-independent, because the notion of an intentional object is a transcendental notion, and issues about mind-dependence do not properly apply within that domain. Szanto writes that "none of the two terms of the intentional correlation is a real entity [...]. Intentional correlation is a relation between entities of sense (Sinnesentitäten) and not between two distinct, respectively independent real-ontological regions" (p. 533). One may wish to obtain more details about the nature of a relation that is said to obtain between non-real entities of sense. But even more pressingly, one wonders how exactly that relation is supposed to shed new light on the question of what it means for a conscious experience to be about some real, transcendent entity. Is transcendental phenomenology at all dealing with this issue, or is it, following an argument that would be suggested by the passages quoted above, dealing with some radically different kind of "intentional correlation"?

Obviously there are various ways to interpret Husserl's transcendental phenomenology. In Chapter 4, Szanto offers an interesting and original interpretation of the relation between Husserl's transcendental idealism and some more recent positions, such as Dummett's antirealism and Putnam's internal realism. Dummett's antirealism, for instance, is characterized as a position that maintains that "the bounds of meaning and understanding are determined by the available evidence [...] that speaks for the truth of some assertion" (p. 536). Transcendental phenomenology, instead, is said to be the view that the bounds of (objective) meaning are determined "through the conditions of possibility of intentional reference to obtaining or non-obtaining objectualities" (p. 536). This might be understood as suggesting that if the aim of some anti-realistic theory of meaning were to show how evidence constrains the possibility of truth, then the aim of a transcendentalphenomenological theory of meaning would be to show how intentionality constrains the possibility of reference. But just as truth itself does not reduce to evidence simply because it is constrained by it, so one may expect that the entities to which one refers in thought do not reduce to mere "Sinnesentitäten" simply because reference to them is constrained by intentionality.

Open Access This article is distributed under the terms of the Creative Commons Attribution License which permits any use, distribution, and reproduction in any medium, provided the original author(s) and the source are credited. 